\title{
Experimental validation of the "target hood static pressure" balancing method for exhaust ventilation systems
}

\author{
Michael Winifred Dodrill \\ West Virginia University
}

Follow this and additional works at: https://researchrepository.wvu.edu/etd

\section{Recommended Citation}

Dodrill, Michael Winifred, "Experimental validation of the "target hood static pressure" balancing method for exhaust ventilation systems" (2004). Graduate Theses, Dissertations, and Problem Reports. 2031. https://researchrepository.wvu.edu/etd/2031

This Thesis is protected by copyright and/or related rights. It has been brought to you by the The Research Repository @ WVU with permission from the rights-holder(s). You are free to use this Thesis in any way that is permitted by the copyright and related rights legislation that applies to your use. For other uses you must obtain permission from the rights-holder(s) directly, unless additional rights are indicated by a Creative Commons license in the record and/ or on the work itself. This Thesis has been accepted for inclusion in WVU Graduate Theses, Dissertations, and Problem Reports collection by an authorized administrator of The Research Repository @ WVU. For more information, please contact researchrepository@mail.wvu.edu. 


\title{
Experimental Validation of the "Target Hood Static Pressure" Balancing Method for Exhaust Ventilation Systems
}

\author{
Michael Winifred Dodrill \\ Thesis submitted to the \\ College of Engineering and Mineral Resources at \\ West Virginia University \\ in partial fulfillment of the requirements \\ for the degree of \\ Master of Science \\ in \\ Industrial Hygiene
}

Steven Guffey Ph.D., Chair

Robert Creese Ph.D.

Kenneth Means Ph.D.

Department of Industrial and Management Systems Engineering.

\author{
Morgantown, West Virginia \\ 2004
}

Key Words:

HVAC Testing and Balancing (TAB), Dampers, Slide-Gates, Blast-Gates, Exhaust ventilation, Airflow, Hood Static Pressure

Copyright 2004 Michael Winifred Dodrill 


\title{
Abstract \\ Experimental Validation of the "Target Hood Static Pressure" Balancing Method for Exhaust Ventilation Systems
}

\author{
Michael Winifred Dodrill
}

An experimental trial of a new method to balance industrial exhaust ventilation systems was performed. Although balance by design is considered preferable, many ventilation systems incorporate dampers to balance the system to a different airflow distribution after installation. The "target hood static pressure" method aims to minimize the time, effort, frustration and confusion invested in the balancing effort. It requires only one and one-half adjustment rounds, can be prepared as a computerized spreadsheet, and substitutes hood static pressure readings for airflow traverse readings. The method also minimizes the system static pressure to the least possible, thereby keeping friction losses at a minimum. Since the resulting distribution errors range less than the measurement error of pitot tube measurements, no method can be demonstrated as being better. 


\section{Acknowledgements}

The author wishes to thank the following for their help and support: Nordfab for donating the ductwork, the graduate committee members for their advice and input and Ahmed El-Sotouhy and Vivek Balasubramanian for helping construct the ventilation system.

\section{Table of Contents}

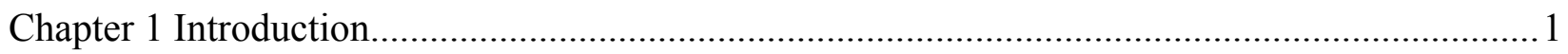

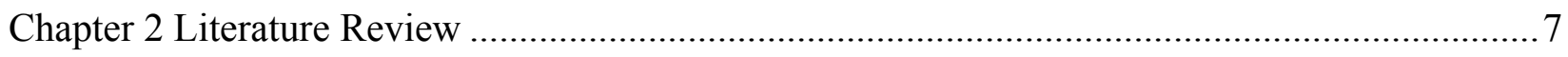

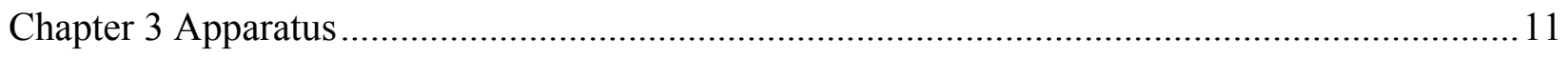

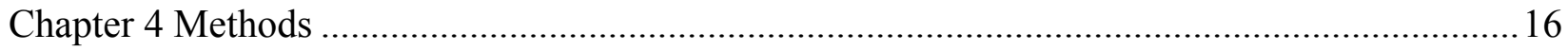

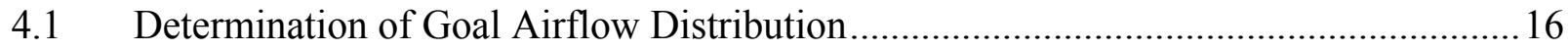

4.2 Prior Measurements of Airflow and Hood Static Pressure ......................................... 16

4.3 Calculation of the Goal Hood Static Pressure for Each Branch at which the System is in

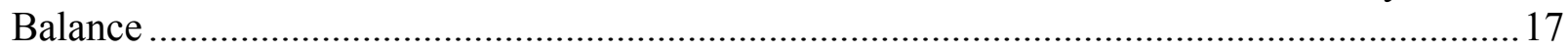

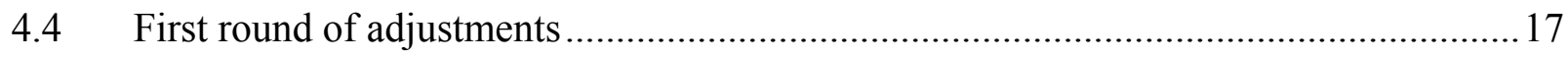

4.4.1 Determination of the Order Factor for the Targets for Round One...................... 18

4.4.2 First Round of Damper Adjustments......................................................20

4.4.3 Evaluation of the First Round of Damper Adjustment......................................20

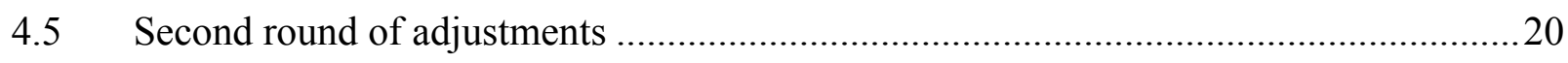

4.5.1 Calculation of the Target Hood Static Pressures for the Second Round of

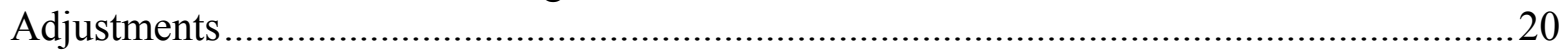

4.5.2 Second Round of Damper Adjustments .......................................................2

4.5.3 Evaluation of the second round of damper adjustments..................................21

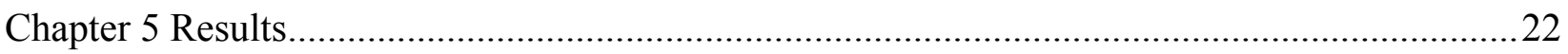

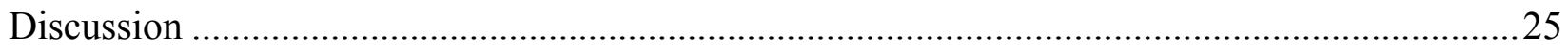

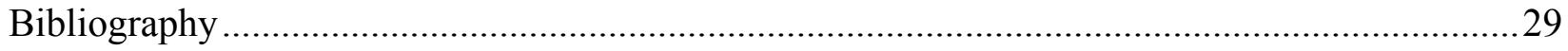

Appendix, Calibration of the Digital Manometer ............................................................ 31 


\section{List of Tables}

Table I - Specifications of the ventilation system used in the study. Lengths are in inches. ........ 14

Table II - Factors for the determination of the target hood static pressure for round 1...............19

Table III - Original, Target and Goal Airflows and Hood Static Pressures ................................. 19

Table IV - Hood Static Pressure and Airflow Results ..........................................................223

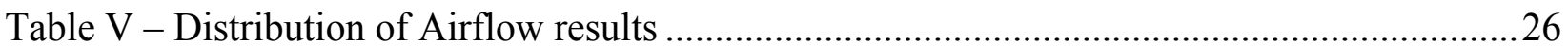

Table VI - Maximum and Root Mean Square Errors ...........................................................2 27

\section{List of Figures}

Figure 1 - Slide Gate Damper Similar to Those Used in This Study. ........................................2

Figure 2 - One of the Slidegates in Fully Open Position .......................................................... 3

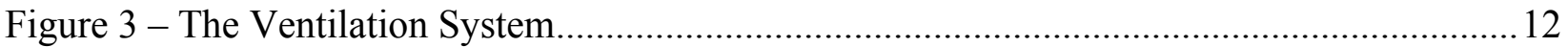

Figure 4 - A Hooded Branch (Branch Number Two) ................................................................ 12

Figure 5 - Schematic of the Experimental Ventilation Duct System...................................... 15 


\section{Abbreviations}

Q

$\mathrm{SPh}$

original Value before balancing when all dampers are completely open

goal

target

$\mathrm{Q}_{(\mathrm{i})}$

Qoriginal

Qoriginal(i)

$\mathrm{Q}_{\text {final }}$

Qgoal

Qgoal(i)

Qtarget

$\mathrm{Q}_{\text {target(i) }}$

$\mathrm{Q}_{\text {fan }}$

Qfan original

Qfan goal

$\mathrm{SP}_{\mathrm{h}}$

$\mathrm{SP}_{\mathrm{h}}$ original

$\mathrm{SP}_{\mathrm{h} \text { goal }}$

$\mathrm{SP}_{\mathrm{h} \text { target round } 1}$

$\mathrm{SP}_{\mathrm{h} \text { round } 1}$

$\mathrm{SP}_{\mathrm{h} \text { target round } 2}$

$\mathrm{SP}_{\mathrm{h} \text { round } 2}$

$\rho_{\mathrm{i}}$

$\rho_{\text {fan }}$

$F_{\text {order }}$

Airflow in cubic feet per minute

Static pressure at the hood in inches water gage

Value that should result with perfect balance

Value to which the practitioner adjusts to

Actual airflow in branch (i)

Airflow before balancing when all dampers are completely open

Airflow in branch (i) before balancing when all dampers are completely open

Actual airflow after balancing

Airflow desired after balancing

Airflow desired in branch (i) after balancing

Airflow to which the balancing practitioner must adjust

Airflow to which the balancing practitioner must adjust in branch (i)

Airflow at the fan

Airflow at the fan before balancing when all dampers are completely open

Airflow at the fan desired after balancing

Hood static pressure

Hood static pressure before balancing when all dampers are completely open

Hood static pressure desired after balancing

Hood static pressure to which the balancing practitioner must adjust in round 1

Hood static pressure after round 1

Hood static pressure to which the balancing practitioner must adjust in round 2 Hood static pressure after round 2

Density of the air in branch "i" in pounds per cubic foot

Density of the air at the fan in pounds per cubic foot

Order-specific modification factors used when calculating $\mathrm{SP}_{\mathrm{h}}$ target round 1 


\section{Chapter 1 Introduction}

Industrial exhaust ventilation systems must be balanced to keep air velocities above a minimum threshold, yet not excessively high. Also, the duct velocity in each branch must be high enough to prevent the settling of particulates if they are present. On the other hand, excessive duct velocities abrade ducts. Erosion is particularly severe at high-friction locations such as elbows. Excessive airflows waste energy and increase operational costs (Jorgensen 1983, p.23-10) as well as increase the noise levels in the workplace. The goal airflow $\left(\mathrm{Q}_{\text {goal }}\right)$ for each branch is chosen so that a) there is enough capture velocity at the hood to ventilate the exhaust source, and b) the air velocity is enough to prevent settling and clogging of ductwork by particulates if any are present.

In balancing ventilation systems, two goals should be met. The most important goal is that every branch of the system has at least its minimal required airflow. The second goal is to reduce the total airflow through the system given that the first goal is met. It does not suffice to have the required airflow on the average. Each branch must have an adequate airflow to ensure that no worker, no matter which branch he is using, is overexposed. Even when the total airflow through the system is enough, some branches may have airflows that are too low, while others are higher than necessary. When some branches have airflows that are too low, then if no change in distribution is attempted, then the total airflow must be increased to the point that all branches have at least their minimally required airflow.

Attaining the lowest total airflow possible requires meeting the first goal at all times. Reducing the total airflow through the system is desirable to minimize erosion of the system, save energy in fan operation and reduce noise from air turbulence. As stated above, each branch should have its minimally required airflow. When some branches have more and others less airflow than what is required, the system operator has two choices, to re-distribute the airflow, or to increase the fan speed.

Balancing a ventilation system is actually an optimization of the system's performance. Balancing a ventilation system involves two actions to meet the two goals. The first action the practitioner undertakes is to distribute the airflows as perfectly as possible. Balancing the system by design, as discussed below, is generally the most efficient method. The other method, also detailed below, is to introduce resistance to airflow by means of "dampers". Secondly, the practitioner adjusts the fan speed as perfectly as possible. In order to have perfect fan speed and 
meet the restriction that every branch have at least its minimum required airflow, the system must be in perfect balance.

The dampers built into industrial ventilation systems take many shapes and forms yet their primary purpose is to enable balancing of the ventilation system. The dampers redistribute airflow by permitting the manipulation of resistance to airflow in each branch. There are two generally used ways to balance an industrial ventilation system. The one generally preferred is to balance the system by design. The other is to balance the system using dampers to add resistance to airflow in the branch. A very common type of damper, and the type used in this study, is the simple slide-gate variety (see Figure 1). The slide-gate, also called "blast-gate", is completely out of the air stream when open, yet effectively seals the branch when shut (Haines 1988) (see Figure 2).

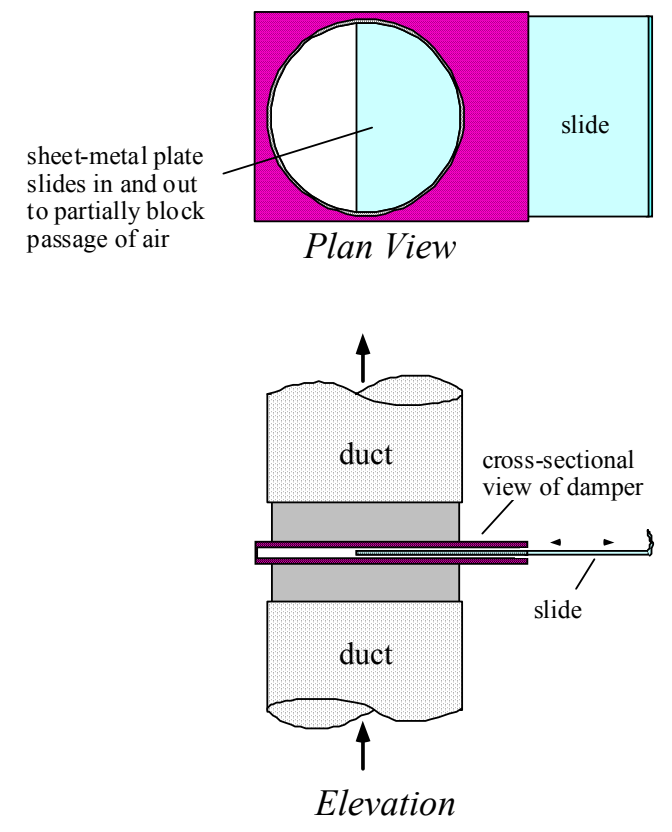

Figure 1 - Slide Gate Damper Similar to Those Used in This Study.

(Figure used by permission of Steven Guffey, Guffey, 2004) 


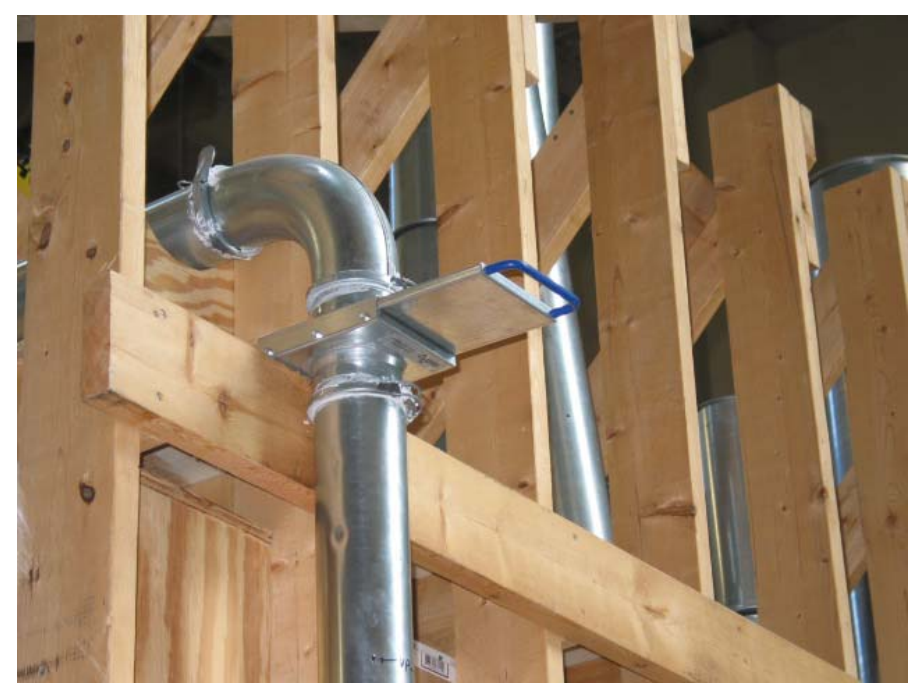

Figure 2 - One of the Slidegates in Fully Open Position

A system with no dampers gives an inflexible distribution of airflow throughout the system. For this reason, many authors recommend balancing the system by design. All branches are designed so that their static pressure losses produce the designed airflow distribution. Choice of duct diameter, duct length, roughness, number of and type of elbows influence the static pressure loss of that branch. (Besant and Asiedu, 2000; Jorgensen, 1983)

The rigidity of the airflow distribution with balance by design can cause problems when the system is modified. An altered system needs its duct diameters changed to maintain the desired airflow distribution through the system (Guffey and Hickey, 1983). If the operator of the system discovers insufficient airflows in some branches and increases the fan speed to maintain minimum required airflows, the other branches will receive excessive airflows. If the distribution of airflow is not changed. In time, the system will need to be re-balanced anyway because of changes to both the system and the needs of the workplace. Process changes often necessitate changes in the minimum airflows due to the amounts, toxicity and settling velocities of the substances ventilated.

A system balanced by means of dampers, on the other hand, has its drawbacks. Dampers inside the system increase resistance, consequently increasing the pressure needed at the fan. Using typical balancing methods (described in following sections), if the fan speed is too high before balancing, the total airflow will be too high. If the practitioner uses branch dampers to both achieve good balance and to reduce fan output to desired levels, the resulting fan pressure may be 
much greater than would have occurred if the fan were adjusted to its ideal speed, thereby wasting energy.

Accumulated debris such as fragments of paper, rags or dust congest the system or catch on the dampers, thereby changing the system performance. Infrequent or no cleaning of the settlement or coating inside the ducts leads to deterioration of the system's performance. In addition, a system that was originally in balance is made ineffective by workers changing the damper settings. The worker opens a damper to counteract an airflow deficiency. The other branches carry less airflow, so those dampers are opened. Soon the situation becomes hopeless.

When balancing the system, it will be shown that the most appropriate goal is to have the right fraction of the total airflow through each branch, not necessarily the right level. It is best to adjust the fan speed after the system is balanced to achieve desired levels. If the practitioner were to balance the system to achieve desired levels when the total fan airflow is too high, all dampers will be inserted more than they need to be and operational efficiency is compromised. Conversely, balancing when the fan speed is too low results in not enough airflow remaining for the last branch. Therefore, if he will adjust the dampers to achieve desired levels instead of fractions, the practitioner must adjust the fan before the system is balanced because the changing of the damper settings during system adjustment changes the total system resistance. When the practitioner closes dampers, system resistance increases and the fan pulls less airflow.

When balancing the system, one must be confident that each airflow in every branch meets or exceeds the goals. Measurement errors using a pitot tube are normally distributed around the true value (Guffey and Booth, 1999). When a measurement in a branch equals the goal, the probability that the true value exceeds the goal is $50 \%$. If the airflow measurement reads less than the goal, the true airflow has less than $50 \%$ chance of meeting or exceeding the goal. Therefore, if the airflow reading is $2 \%$ below the goal airflow, and the standard deviation is 3\% (Guffey and Booth, 1999), there is less than $27 \%$ chance of the true airflow meeting or exceeding the goal.

In order to increase the confidence that all branches meet their goal airflows, the balancing practitioner should take the pitot tube measurements at face value, adjust exactly to the targets, and increase the fan airflow a fraction above the goal fan airflow. If the practitioner takes the readings at face value without considering measurement error, and ensures that the condition that every branch's required airflow is satisfied, there is a $50 \%$ probability that the most starved branch truly has its minimum airflow requirement. For the other branches, the probabilities that 
they meet their requirements increase. For these reasons, the practitioner should put the safety factor into the setting of the fan speed, and balance exactly to the targets when balancing the branches. A safety factor of three or five percent in the fan speed increases the probability of the lowest branch meeting its required airflow. Increasing the fan speed increases all branch airflows proportionately and helps accommodate deterioration of system performance over time.

If a measurement of airflow lies below its goal, the practitioner cannot disregard the apparent deficiency by attributing it to measurement error. For example, if the measurement error of an airflow-measuring device is 3\% and the practitioner measured the airflow in a duct as being 3\% below its goal, the airflow might well be deficient. The reason is that the actual airflow might be $6 \%$ below the goal and the 3\% measurement error made the reading 3\% higher than the true value. The range of error lies on both sides of the true value. A 3\% error can be either positive or negative - in a range $6 \%$ wide.

The ideal method for industrial exhaust ventilation systems would be effective and easy to use. It would necessitate very few rounds of adjustment to bring the system into perfect balance. After balancing, the system has the correct distribution of airflow in each branch. At least one damper remains completely open to keep at minimum the losses in system operation and maximize operational efficiency. The ideal method has rational and easily obtainable goals to direct the practitioner and eliminate confusion. These goals are independent of the fan speed. Even if the airflows are incorrect after balancing, the correct proportion of airflow exists in each branch and only the fan needs adjustment. This means that a system can be balanced before its proper fan is installed. Finally, the time and effort the practitioner invests is minimal.

The "Target Hood Static Pressure" method tested is designed to be easier to execute than the methods currently in use. This method applies one-and-one-half rounds of adjustment rather than three rounds as required by other methods. The goal airflows for each branch are converted to static pressure values (see Equation 4). The practitioner adjusts the damper until the manometer

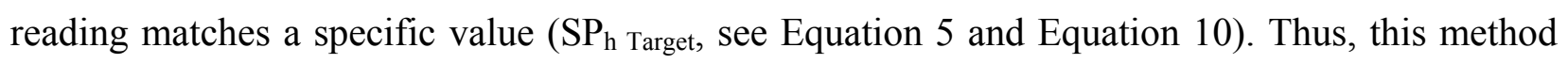
provides clear and specific goals already converted to the units the practitioner measures. This method is easily set-up in a computerized spreadsheet to instantly obtain the target values based on input information without additional, on-site calculations. Since the centerline hood static pressure stands in for the velocity pressure traverse required by the other methods, the balancing practitioner takes only one reading instead of twenty. For each balancing trial in this study, the 
author needed about four hours from start to finish including equipment preparation and calibration. Furthermore, the investigator carried out all experimentation as a without an assistant. This study ran two trials each of two different sets of goal airflow distributions. These goal airflows differed from the branches' original airflows (when all dampers are completely open) by as much as $30 \%$. These goal distributions aimed to challenge the method by providing large opportunity for error.

Statistical analysis of the results could not be performed because branch errors are mutually dependent, violating a requirement for statistical analysis. For this reason, the author uses a measure of the wasted fraction of airflow. The "fraction wasted" (Equation 1) is the amount of the total airflow at the fan above the sum of hood target airflows provided that the most deficient branch has exactly its required airflow. The most deficient branch is the one whose ratio $Q_{i} /$ $\mathrm{Qgoal}_{(\mathrm{i})}$ is the lowest, expressed as $\min \left\{\mathrm{Q}_{\mathrm{i}} / \mathrm{Qgoal}_{(\mathrm{i})}\right\}$. Each branch's airflow will equal at least its goal airflow and $\min \left\{\mathrm{Q}_{\mathrm{i}} / \mathrm{Q}_{\mathrm{goal}}(\mathrm{i})\right\}$ will equal 1 after the fan airflow is adjusted to the point that the fraction wasted is zero.

$$
\text { Fraction Wasted }=\left[\frac{1}{\min \left\{\frac{Q_{i}}{Q_{\text {goal }(i)}}\right\}} \times \frac{Q_{\text {fan }}}{Q_{\text {fangoal }}}\right]-1
$$

(Source: Steven Guffey (2004) unpublished manuscript)

The $\min \left\{Q_{\mathrm{i}} / \mathrm{Qgoal}_{(\mathrm{i})}\right\}$ term is the lowest value from all the branch airflow to goal airflow ratios. The inverse of this ratio multiplied by the ratio of actual fan airflow to the sum of the goal mass airflows for each branch gives the fraction of goal airflow present. The fraction of goal airflow minus one yields the fraction of the fan airflow that is wasted. Since the author could not find any published results of balancing trials, he had no data to compare. The calculation of fraction wasted makes comparison to other balancing trials possible. 


\section{Chapter 2 Literature Review}

Literature from the heating, ventilation and air conditioning industry outlines methods used for duct systems. The Sheet Metal and Air Conditioning Contractors' National Association (SMACNA 1993), American Society of Heating, Refrigerating and Air-Conditioning Engineers (ASHRAE 1995) and the American Conference of Governmental Industrial Hygienists (ACGIH 2001) all publish methods in their manuals. SMACNA presents two methods for supply air systems in its testing, adjusting and balancing guidebook, the "stepwise method" and the proportional balancing (ratio) method (SMACNA 1993).

Although the SMACNA methods are designed for supply systems, they conceivably could be applied to exhaust systems. The "stepwise method" is the easier of the two to understand. In the first adjusting pass, those terminals with high airflows are adjusted until their airflows undercut their design airflows by $10 \%$. Thus the first pass is a partial round in which branches are adjusted only if they initially had excessive airflows. The second adjusting pass uses the goal airflows as the targets to which the practitioner adjusts. A possible third pass aims to put right any significant deviations from the desired air distribution.

The SMACNA proportional (ratio) method involves more mathematical preparation and is more methodical. The procedure is not explained clearly, and some steps appear to be omitted, but the following is probably what is intended. First, when all dampers are open, the airflow is recorded in each branch. Then, the percentage of each branch's design airflow is calculated in order to rank the branches into the sequence for adjustment. Based on the percent of design airflow, the branches are balanced in sequence from the lowest (most starved) branch to the highest (most excessive). The lowest branch is left alone (its damper left completely open). The second lowest branch is adjusted until its airflow comes to halfway betweens its original value and that of the first (most starved) branch. The airflow of the first branch should come up to equal about the same airflow. Next, the third branch is adjusted until its airflow value equals what appears to be the average of the original airflows for the first three branches. The balancing is continued in this way proportionately for the rest of the branches.

SMACNA is not explicit on how to derive the target airflow for each branch for adjusting. This target appears to equal the average of the pre-balancing (all dampers open) airflows for the branch being balanced and all the preceding branches. Unlike the other methods and the method at the focus of this study, the sequence of balancing begins with the most starved branch in 
reverse order. Both of SMACNA's methods remain unchanged from its 1993 HVAC Systems Testing Adjusting \& Balancing handbook to its 2003 TAB Procedural Guide.

SMACNA's HVAC Systems Testing, Adjusting and Balancing manual specifically states to adjust the fan before balancing to yield the needed total airflow (SMACNA 1993 p.12.3). However, SMACNA fails to address the need to readjust the fan after balancing. SMACNA also uses the goal airflow as the target for its "stepwise" method. This means that some branches will have airflows that are too high to varying degrees.

ASHRAE prefers another proportional method for system balancing. Their proportional method, like the other methods, begins with each damper fully opened. ASHRAE requires tuning the fan speed so that the airflow at the fan equals the design fan airflow. The practitioner then balances each branch "proportionately" to each other. Even though ASHRAE recommends to "concentrate on balancing to the proportion rather than the absolute value", they are neither explicit in how to do this, nor in what to use as target values. Furthermore, ASHRAE states that several passes could be needed (ASHRAE 1995 p. 34.4).

The ACGIH gives no specific procedure to balance an existing ventilation system. Their manual covers balancing a system by design and gives advice on tuning operational systems. Instructions are given on calculating the damper settings based on a thorough characterization of the system. No method is given for balancing without calculation of the friction losses.

Another method has been described by Guffey (1993). This method employs the ratio of the hood static pressures at the end of the branches. Guffey claims this method will produce nearly perfect distributions in one round, but it requires computations that are difficult to do without computer coding.

When balancing ventilation systems, it is crucial to adjust to the proper ratio of branch airflow to branch goal airflow. Once the desired distribution is achieved, the fan is adjusted to bring the airflows to their proper amount. Thus, one must balance to a ratio of $\mathrm{Q}_{(\mathrm{i})} / \mathrm{Q}_{\text {goal(i) }}$ such that by the conclusion of balancing, each branch's $\mathrm{Q}_{(\mathrm{i})} / \mathrm{Q}_{\text {goal(i) }}$ ratio equals to the same value.

The lowest extreme for the behavior of $\mathrm{Q}_{(\mathrm{i})} / \mathrm{Q}_{\mathrm{goal}(\mathrm{i})}$ ratios as dampers are adjusted would be the case when any decrease in a duct airflow results in an equal decrease in the total airflow at the fan (Guffey, 2004). As one closes a damper, the total fan airflow decreases by the exactly the same amount as the airflow in the branch did on which the damper was closed. Consequently, if the 
dampers are perfectly adjusted, each branch's airflow equals the minimum $Q_{(i)} / Q_{\text {goal(i) }}$ ratio. At the start, $Q_{\text {original(i) }} / \mathrm{Q}_{\text {fan original }}$ equals the fraction of airflow through each branch. If the reduction in airflow at the fan is the same as the reduction of airflow in branch "i", changing the damper in branch "i" does not change the airflow in any of the other branches. If this extreme is true, then the ratio $\mathrm{Q}_{(\mathrm{i})} / \mathrm{Q}_{\text {goal(i) }}$ equals the percentage by which $\mathrm{Q}_{(\mathrm{i})}$ must be reduced to meet our goal distribution. The goal is for all $\mathrm{Q}_{(\mathrm{i})} / \mathrm{Q}_{\mathrm{goal}}$ (i) ratios to equal the same value. If this extreme is true, and the system is in perfect balance, all ratios are the same and they equal what was originally the most starved branch (the one with the lowest $\mathrm{Q}_{\text {original(i) }} / \mathrm{Q}_{\mathrm{fan} \text { original }}$ ratio).

The other extreme is that the airflow at the fan always stays the same (Guffey, 2004). If shutting a damper has no effect on $\mathrm{Q}_{\text {fan }}$, then the ratio of $\mathrm{Q}_{\mathrm{fan}} / \mathrm{Q}_{\mathrm{fan} \text { goal }}$ remains constant. If the system is in perfect balance then every $\mathrm{Q}_{(\mathrm{i})} / \mathrm{Q}_{\text {goal(i) }}$ equals $\mathrm{Q}_{\text {fan }} / \mathrm{Q}_{\text {fan goal }}$. For example, when the system is in

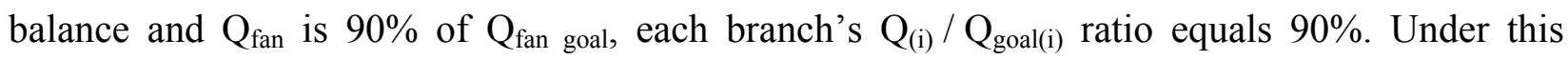
scheme, the target $\mathrm{Q}_{(\mathrm{i})} / \mathrm{Q}_{\mathrm{goal}(\mathrm{i})}$ for any branch can be predicted because it comes to the average ratio of all other branches.

The way $\mathrm{Q}_{(\mathrm{i})} / \mathrm{Q}_{\text {goal(i) }}$ changes with damper regulation in real ventilation systems lies somewhere in-between these two limits. Although it is possible to identify where the behavior lies for a given fan and system with a good deal of study and fan modeling, few practitioners would be willing or able to do this. For that reason, Guffey (2004) proposed to simply use the average of the two extreme cases.

The order in which the dampers are adjusted also affects the target airflow in each branch. The earlier in the order of balancing the damper adjustment is, the greater the difference between $\mathrm{Q}_{\text {target(i) }}$ and $\mathrm{Q}_{\text {goal(i). }}$. The first damper adjustment has the greatest impact on all duct airflows. The later in the sequence, the lower the overall system resistance is and the less a damper will need to be inserted. The $\mathrm{Q}_{\text {target }}$ value for each branch to which the damper is adjusted is a value different from the goal airflow such that by the end of the balancing sequence, each branch's $\mathrm{Q}_{(\mathrm{i})}$ equals or

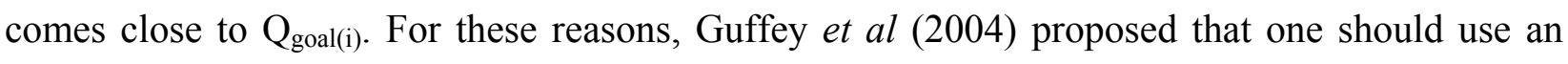
order-based modification factor for each branch that is found by multiplying that branch's goal to obtain the target. Guffey et al established these modification factors by trial-and-error using spreadsheet models.

For the second round, Guffey proposed that only half of the dampers need to be adjusted. The dampers are adjusted in the order of the magnitudes (i.e., positive or negative) of their deviations 
from the median ratio, $\mathrm{Q}_{\mathrm{i}} / \mathrm{Q}_{\mathrm{goal}}$ (i), at the end of the first round of adjustment. Unlike the first round of adjustments, an order factor is not used for the second round of damper adjustments. 


\section{Chapter 3 Apparatus}

This study was performed on a full-sized exhaust ventilation system in the West Virginia University Ventilation and Exposure Assessment Laboratory (see Figure 3). The system had seven branches, each designed to have different resistances to flow by variation of duct length, number of elbows and type of hood transition (see Figure 4, Figure 5 and Table I). The 20-gauge, galvanized steel ductwork was manufactured and donated by Nordfab®. Duct sections were clamped to other duct sections, elbows, and junction fittings. For this study, these connections were clamped shut and sealed with caulking to eliminate air leakage. Duct system airflow was provided by an Aerovent Fan No. 315BI-SWCB-3435-3 Type SWCB Ser. 8708562-001.

A TSI DP-Calc digital manometer (Model: 8702) was used in conjunction with a standard Dwyer Pitot tube for all static pressure and velocity pressure readings. The author used a custom-made device (Guffey,1990) to hold the Pitot tube, with interchangeable scales that were pre-marked to the insertion depths for each duct diameter. The measurements of the hood static pressure and the 10-point log-linear Pitot traverses for velocity pressure were done as detailed in Industrial Ventilation (2001, pp 9-9 through 9-11). Hood static pressures were measured four duct diameters from the start of the straight duct exiting the hood or, in the case of no hood, from the end of the duct. Velocity pressures were measured eight duct diameters from the beginning of the first straight section to allow the air-stream to stabilize. 


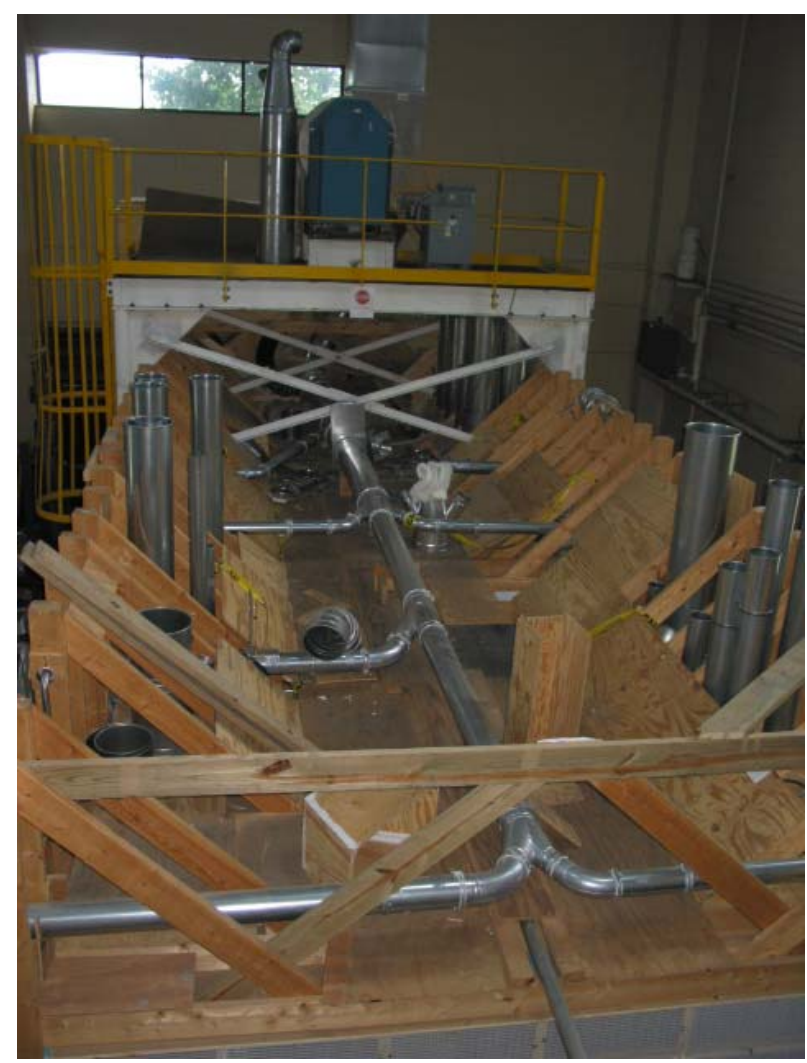

Figure 3 - The Ventilation System

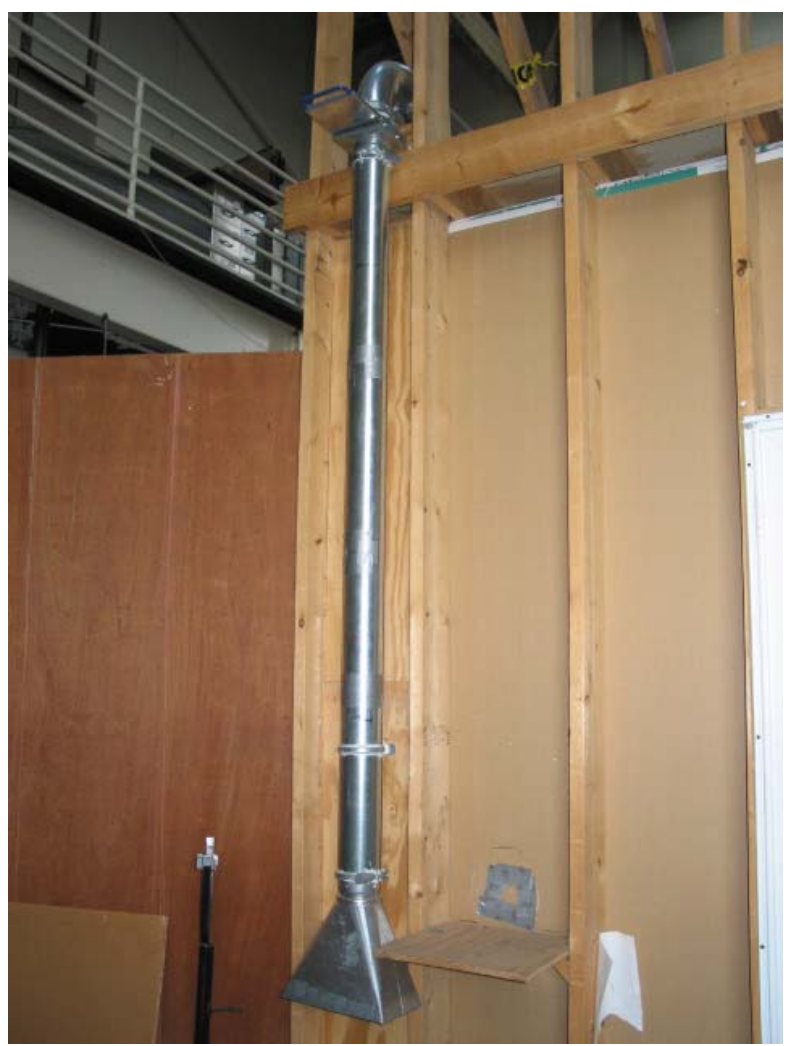

Figure 4 - A Hooded Branch (Branch Number Two) 
When measuring velocity pressure, the author set the manometer time constant to one second. For the static pressure measurements, the author used the five-second time constant. During the adjusting of the dampers, the author used the one-second time integration because of the variability of the readings while the hood static pressure was in flux.

The digital manometer was calibrated using a Dwyer Instruments Inc. Pressure No. 1425 Hook Gage. After leaving the manometer on for at least an half hour to stabilize, the reading was checked against water levels at $1 / 4,1 / 2,3 / 4,1,1 \frac{1}{2}, 2,3,4,5$ and 6 inches. This range covers the range of readings during measurement of the ventilation system. The manometer was calibrated immediately before all measurements. See the appendix for all calibration results. 
Table I - Specifications of the ventilation system used in the study. Lengths are in inches.

\begin{tabular}{|c|c|c|c|c|c|c|c|c|c|c|c|c|}
\hline 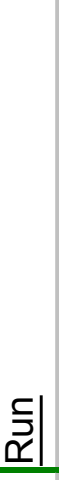 & 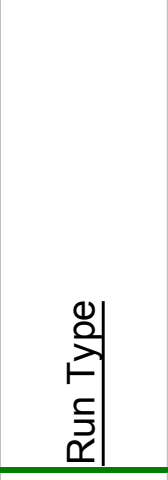 & 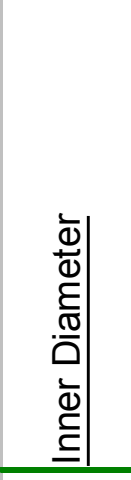 & 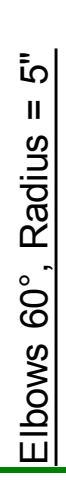 & 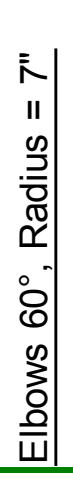 & 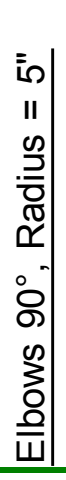 & 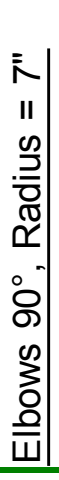 & 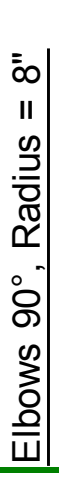 & $\begin{array}{l}\text { क् } \\
\frac{1}{0} \\
\text { 을 }\end{array}$ & 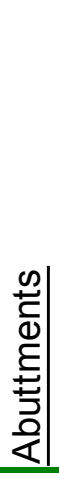 & 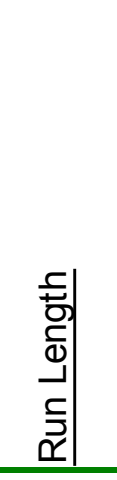 & 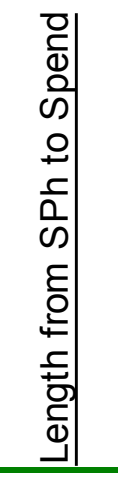 & 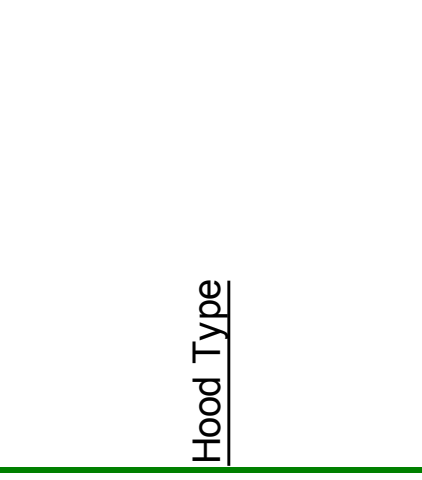 \\
\hline & & & & & & & & & & & & \\
\hline 1 & Branch & 4.8506 & & 1 & & & 1 & 1 & 6 & 169 & 116 & Naked \\
\hline 2 & Branch & 3.8411 & 1 & & & 1 & & 1 & 8 & 173 & 136.5 & $12 " \times 6 "$ opening. 9" deep \\
\hline 3 & Branch & 4.8506 & & 1 & & & 1 & 1 & 7 & 169 & 103 & $12 " \times 6 "$ opening. 9" deep \\
\hline 4 & Branch & 3.8411 & 1 & & & 1 & & 1 & 7 & 177.5 & 147 & Naked \\
\hline 5 & Branch & 3.8411 & 1 & & & 1 & & 1 & 7 & 165 & 133 & $12 " \times 6 "$ opening. 9" deep \\
\hline 6 & Branch & 4.8506 & 1 & & 2 & & & 3 & 11 & 294.5 & 273.5 & Naked \\
\hline 7 & Branch & 3.8411 & 1 & & 2 & 2 & & 5 & 17 & 319.5 & 287 & Naked \\
\hline 10 & Submain & 5.862 & & & & & & & 3 & 93 & & \\
\hline 20 & Submain & 6.874 & & & & & & & 2 & 84 & & \\
\hline 30 & Submain & 10 & & & & & & & 3 & 101 & & \\
\hline 40 & Main & 12 & & & & & & & 1 & 44 & & \\
\hline
\end{tabular}




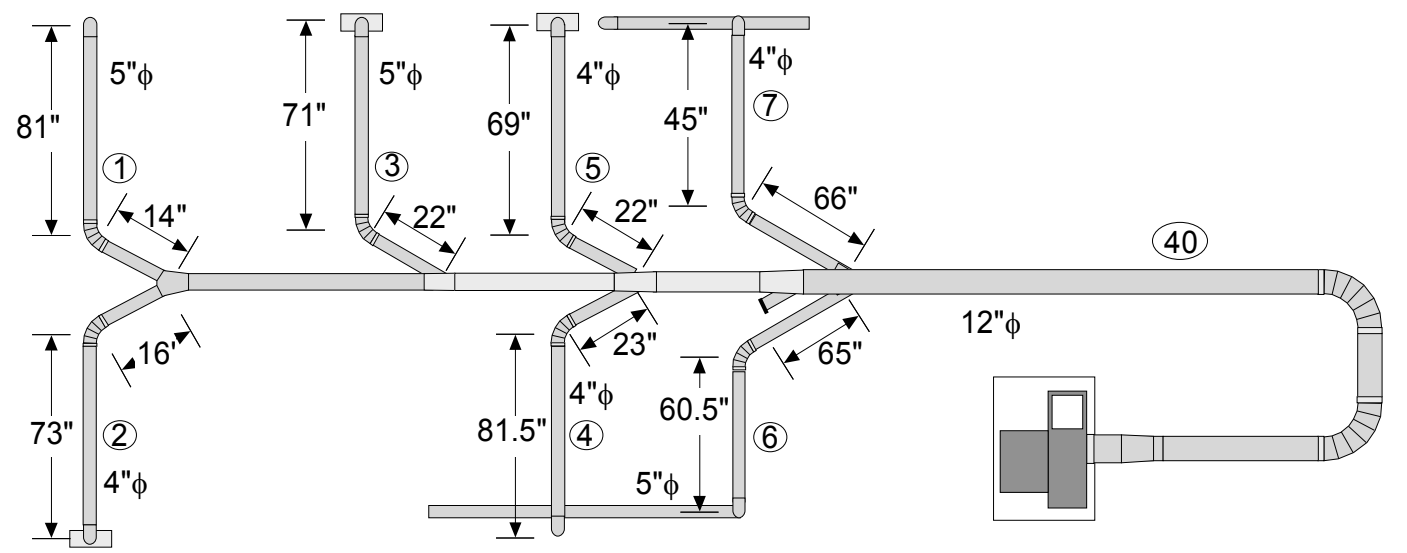

\section{Plan View}

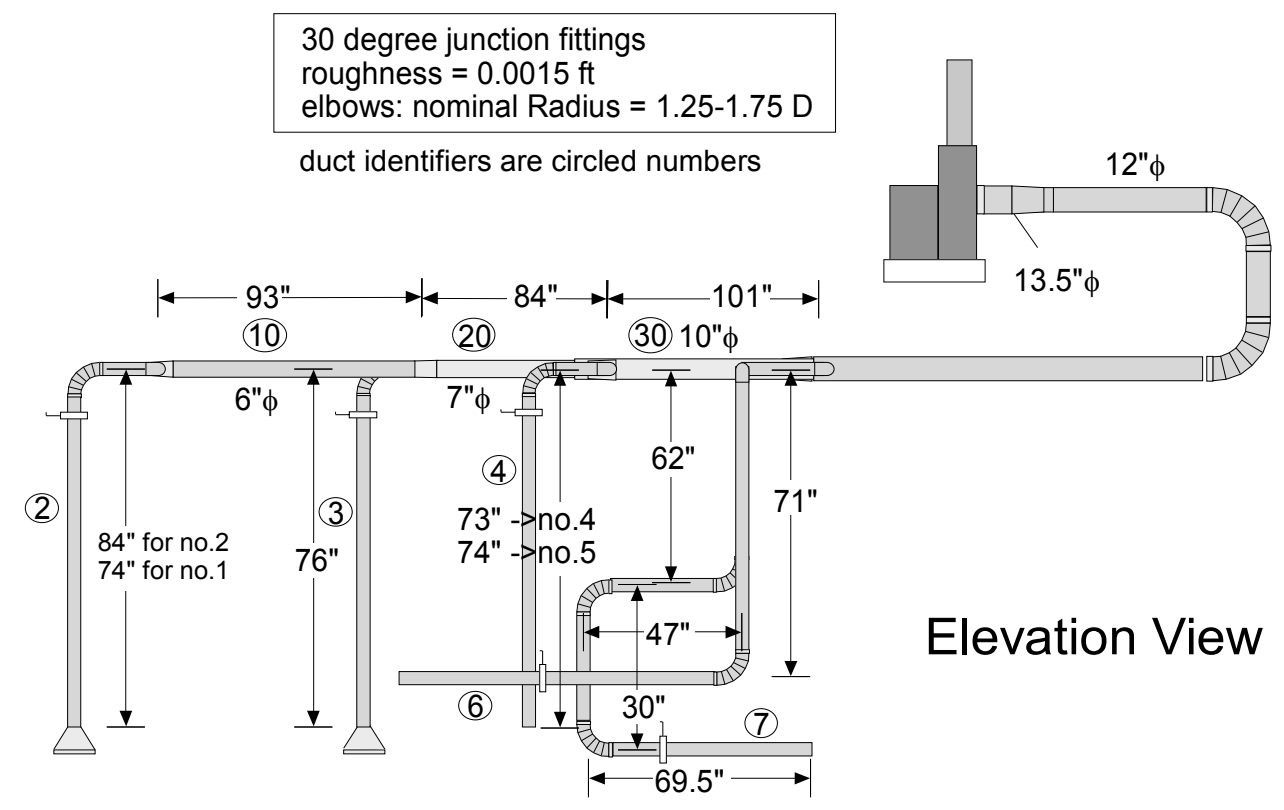

Figure 5 - Schematic of the Experimental Ventilation Duct System 


\section{Chapter 4 Methods}

This study tests the "Target Hood Static Pressure" method presented by Guffey (2004). This method discriminates from the published methods covered in the introduction in that it uses hood static pressure readings rather than airflow measurements. McLoone, H.E.; Guffey, S.E. and Curran, J.C. (1993) demonstrated that hood static pressure in a duct is proportional to airflow squared. The practitioner is expected to carry out the steps detailed in the methods below, measuring airflows only initially and stopping with the evaluation of the hood static pressures after round two. The author conducted further measurements of the final airflows and presents their analysis in the discussion.

\subsection{Determination of Goal Airflow Distribution}

In field practice, $Q_{\text {goal }}$ for each branch is chosen so that there is enough airflow that the hood can control contaminants adequately. In addition, the diameter of the duct is selected to insure that a specified minimum duct velocity is met or exceeded to prevent settling of particulates in the duct. If the airflow is reduced in an operating system, the duct velocity must continue to meet or exceed the specified minimum. This means both the hood airflow requirement and the airflow necessary to maintain the duct velocity, thereby setting a minimum allowable airflow for the duct. For this study, neither issue existed. Instead, the author chose the goal airflow distributions for this study to substantially challenge the method. As seen in Table IV and Table V, the shift in airflows was as much as $30 \%$ of the original airflows, a relatively large change.

The goal for fan airflow is simply the mass rate of flow through the hoods divided by the air density at the fan:

$$
\mathrm{Q}_{\text {fan goal }}=\frac{\sum_{i=1}^{n}\left(\rho_{i} \times Q_{\text {goal }(i)}\right)}{\rho_{\text {fan }}}
$$

\subsection{Prior Measurements of Airflow and Hood Static Pressure}

Before commencing with any attempt to balance the dampers, the hood static pressure $\left(\mathrm{SP}_{h}\right)$ and velocity pressure traverses of each branch must be recorded with all dampers completely open. The airflows of each branch are calculated from the velocity pressure (VP) readings as specified in the Industrial Ventilation Manual (ACGIH, 2001). The airflow at the fan is the sum of the mass flows at the branches divided by the density at the fan (Equation 2). For the system tested here, 
the densities were the same everywhere because the branches were drawing from the room air. Thus, the airflow at the fan $\left(\mathrm{Q}_{\mathrm{fan}}\right)$ was simply the sum of the airflows through the branches.

Airflow is computed by multiplying the air velocity determined by pitot traverse by crosssectional area of the duct.

$$
\mathrm{Q}=\mathrm{V} \times \mathrm{A}
$$

Unless it is possible to increase fan output (i.e., by increasing rotation rate), the total fan airflow of the target airflow distribution $\left(\mathrm{Q}_{\text {fan goal }}\right)$ cannot be larger than the fan airflow. If $\mathrm{Q}_{\text {fan goal }}$ is larger than $\mathrm{Q}_{\text {fan }}$ with all dampers open, the fan must be adjusted either before or after adjusting the dampers to pull the needed airflow.

\subsection{Calculation of the Goal Hood Static Pressure for Each Branch at which the System is in Balance}

The published methods for balancing described in the introduction generally use the airflow as the target. Since hood static pressure is proportional to duct airflow squared for each branch (McLoone, Guffey and Curran 1993) values of SPh can be used in place of airflows in setting dampers. Determining airflow requires taking multiple velocity pressure readings at points along one or more traverses through the cross-section of the duct. Measuring $\mathrm{SP}_{\mathrm{h}}$ is almost always much faster and more convenient than measuring velocities. For that reason, the "Target Hood Static Pressure" method employs $\mathrm{SP}_{\mathrm{h}}$ values instead of airflow values in setting targets and goals for damper adjustment.

The hood static pressure value for a particular branch at which its airflow should match its goal airflow is calculated as follows:

$$
\mathrm{SP}_{\mathrm{h} \text { goal }(\mathrm{i})}=\mathrm{SP}_{\mathrm{h} \text { original }(\mathrm{i})} \times\left(\mathrm{Q}_{\text {goal(i) }} / \mathrm{Q}_{\text {original }(\mathrm{i})}\right)^{2}
$$

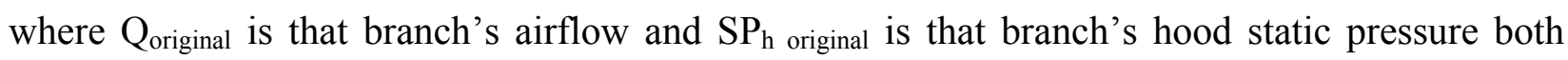
measured when all dampers on the entire system were fully opened. Qgoal is that branch's airflow desired after balancing.

\subsection{First round of adjustments}

As the damper on one branch is closed, the resistance to airflow increases in that branch and the airflow through the other branches increases. Thus, if one adjusts the damper on the first branch exactly to our goal value, then proceeds to do the same on the second branch, one will see that the 
airflow in the first branch increased. Continuing this scheme will result in most of the branches having airflows that are too high, forcing additional rounds of adjustments.

Instead, one should adjust to a target level $\left(\mathrm{SP}_{\mathrm{h} \text { target }}\right)$ that is somewhat lower than the goal for most ducts. The first duct adjusted would have the greatest reduction and subsequent ducts adjusted should be increasingly close to the goal value. Therefore the $\mathrm{SP}_{\mathrm{h}}$ target value for each duct should depend not only on $\mathrm{SP}_{\mathrm{h} \text { goal }}$ but also on the sequence in which dampers are adjusted.

$$
\mathrm{SP}_{\mathrm{h} \text { target round } 1}=(\text { Target Ratio })^{2} \times \mathrm{SP}_{\mathrm{h} \text { goal }} \times\left(\mathrm{F}_{\text {order }=\mathrm{n}}\right)^{2}
$$

Where

$$
\text { Target Ratio }=\frac{\min \left\{\frac{Q_{i}}{Q_{\text {goal }(i)}}\right\}+\left\{\frac{Q_{\text {fan }}}{Q_{\text {fangoal }}}\right\}}{2}
$$

The target ratio assumes that the real behavior of the ratio of $\mathrm{Q}_{(\mathrm{i})} / \mathrm{Q}_{\text {goal(i) }}$ lies between the extremes detailed in the introduction. Equation 6 assumes that the ratio equals the average of the minimum of all branch $\mathrm{Q}_{(\mathrm{i})} / \mathrm{Q}_{\text {goal(i) }}$ ratio and the fan ratio. In real systems, as described in the introduction, the airflows of the branches as well as the airflow at the fan change when a damper is re-set.

Values of $\mathrm{SP}_{\mathrm{h}}$ target for round 1 are shown in Table III. The basis for determining the order factor is discussed in following section.

\subsubsection{Determination of the Order Factor for the Targets for Round One}

To determine the sequence for balancing, first determine each branch's airflow ratio.

$$
\mathrm{Q}_{\text {ratio }}=\mathrm{Q}_{\text {original }} / \mathrm{Q}_{\mathrm{goal}}
$$

The higher the ratio, the greater the difference is between the airflows before and after balancing. A damper change on a branch with higher airflow ratio should have more impact on the airflow distribution through the entire system than a damper change on a branch with lower airflow ratio. For this reason, the higher the airflow ratio of a branch, the greater its priority for balancing in order that the greatest impact on balance is settled early in the balancing round.

$$
\begin{aligned}
& \text { Order }= \text { rank position decreasing with increasing value of } \\
& \mathrm{Q}_{\text {original(i) }} / \mathrm{Q}_{\text {goal (i) }}
\end{aligned}
$$


The highest ratio branch ranks first and is adjusted first, the second highest ratio branch second, and so on to the lowest ratio branch at the last place in the order, which is not adjusted at all. When all other branches have been adjusted perfectly, the last branch should already have its goal proportion of airflow.

Table II - Factors for the determination of the target hood static pressure for round 1

\begin{tabular}{|l|l|}
\hline$F_{\text {order }=1}$ & 0.90 \\
\hline$F_{\text {order }}=2$ & 0.95 \\
\hline$F_{\text {order }}=3$ & 0.97 \\
\hline$F_{\text {order }=4}$ & 0.98 \\
\hline$F_{\text {order }=5}$ & 0.99 \\
\hline$F_{\text {order }}=6$ & 1.00 \\
\hline
\end{tabular}

Guffey et al (2004) determined the values for the order factors listed in Table II by trialand-error by using several different computerized spreadsheets modeling ventilation system behavior. The order factors plot on a mathematical curve such that the number of branches in the order determines the density of points on the curve. Each point lies the same distance apart on the axis below the curve.

Table III records the original, target and goals values for both distribution used for this study.

Table III - Original, Target and Goal Airflows and Hood Static Pressures (airflows in $\mathrm{ft}^{3} / \mathrm{min}$, Hood Static Pressures in inches water gage)

\begin{tabular}{cccccccc}
\hline Distribution & Branch & $\mathbf{Q}_{\text {original }}$ & $\mathbf{Q}_{\text {goal }}$ & Order round 1 & $\mathbf{S P}_{\mathbf{h} \text { original }}$ & $\mathbf{S P}_{\mathbf{h ~ g o a l ~}}$ & $\mathbf{S P}_{\mathbf{h} \text { target round } \mathbf{~}}$ \\
\hline A & 1 & 404.7 & 350 & 4 & 0.930 & 0.696 & 0.538 \\
A & 2 & 279.2 & 360 & 6 & 0.799 & 1.328 & 1.069 \\
A & 3 & 481.7 & 400 & 3 & 0.978 & 0.674 & 0.511 \\
A & 4 & 307.6 & 400 & 7 & 1.199 & 2.028 & 1.632 \\
A & 5 & 325.8 & 380 & 5 & 1.121 & 1.525 & 1.203 \\
A & 6 & 397.5 & 290 & 1 & 0.909 & 0.484 & 0.315 \\
A & 7 & 223.3 & 180 & 2 & 0.654 & 0.425 & 0.309 \\
& & & & & & & \\
B & 1 & 404.7 & 500 & 7 & 0.930 & 1.420 & 1.097 \\
B & 2 & 279.2 & 250 & 2 & 0.799 & 0.641 & 0.447 \\
B & 3 & 481.7 & 520 & 4 & 0.978 & 1.140 & 0.846 \\
B & 4 & 307.6 & 225 & 1 & 1.199 & 0.642 & 0.402 \\
B & 5 & 325.8 & 330 & 3 & 1.121 & 1.150 & 0.836 \\
B & 6 & 397.5 & 450 & 5 & 0.909 & 1.165 & 0.882 \\
B & 7 & 223.3 & 275 & 6 & 0.654 & 0.992 & 0.766 \\
\hline
\end{tabular}




\subsubsection{First Round of Damper Adjustments}

Before commencement of the first round of damper adjustments, all dampers should be completely opened and the fan turned on. The person balancing the system starts with the first branch in the order of adjustment (from Equation 8). While measuring $\mathrm{SP}_{\mathrm{h}}$, he closes the damper

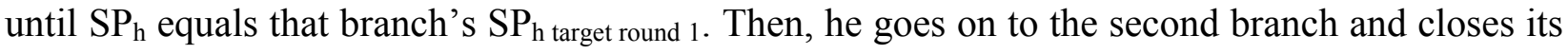
damper until $\mathrm{SP}_{\mathrm{h}}$ equals $\mathrm{SP}_{\mathrm{h}}$ target round 1 for branch order two. The person balancing repeats this procedure until reaching to the last branch in the sequence. Ideally, the hood static pressure in the last branch in the sequence should match goal hood static pressure, in any case, its damper should be left completely open.

\subsubsection{Evaluation of the First Round of Damper Adjustment}

To evaluate the first round of damper adjustments, collect hood static pressure readings from each branch and calculate each branch's hood static pressure ratio:

$$
\mathrm{SP}_{\mathrm{h}} \text { Ratio Round } 1=\mathrm{SP}_{\mathrm{h} \text { round } 1} / \mathrm{SP}_{\mathrm{h} \text { goal }}
$$

The ratio for each branch should be more or less the same value. That half of the number of branches whose $\mathrm{SP}_{\mathrm{h}}$ Ratio differs from the median $\mathrm{SP}_{\mathrm{h}}$ Ratio by more than $2 \%$ are considered for re-adjustment. In the second round of adjustment, the order is unimportant because the values are close to their goals and because some dampers are opened more while others are inserted. The author started with the branch most different from the median ratio and went to the least different branch only to be consistent and avoid confusion.

\subsection{Second round of adjustments}

\subsubsection{Calculation of the Target Hood Static Pressures for the Second Round of Adjustments}

After the first round of damper adjustments is complete, one should measure all $\mathrm{SP}_{\mathrm{h}}$ values again. The target hood static pressures to adjust to for the second round of adjustment are calculated by multiplying the median hood static pressure ratio (that is, the median from each branch's result from Equation 9) for round one by the goal static pressure thus:

$$
\mathrm{SP}_{\mathrm{h} \text { target round } 2}=\text { Median } \mathrm{SP}_{\mathrm{h}} \text { Ratio After Round } 1 \times \mathrm{SP}_{\mathrm{h} \text { goal }}
$$




\subsubsection{Second Round of Damper Adjustments}

The second round of adjustments is carried out like the first except that only about half the branches are re-adjusted, the target hood static pressures are different, and the balancing sequence does not matter. Only modest corrections, either pulling out or inserting, are made in the damper.

\subsubsection{Evaluation of the second round of damper adjustments}

After adjusting the last damper, one should measure all the $\mathrm{SP}_{\mathrm{h}}$ values one last time and compute $\mathrm{SP}_{\mathrm{h}} / \mathrm{SP}_{\text {goal }}$ for each branch. If all ratios are within $6 \%$, no further damper adjustments are necessary. The evaluation of the second round is identical to the evaluation of the first round (see Equation 9).

$$
\mathrm{SP}_{\mathrm{h}} \text { Ratio Round } 2=\mathrm{SP}_{\mathrm{h} \text { round } 2} / \mathrm{SP}_{\mathrm{h} \text { goal }}
$$

For the purposes of this study, pitot traverses were done again for all branches to determine final airflows. 


\section{Chapter 5 Results}

Table IV contains the hood static pressure and airflow results of the balancing trials using the proposed method, including the values of initial, between round, final and goal values. Note that the values of $\mathrm{SP}_{\mathrm{h}}$ start at the initial values and increase monotonically to the final values. The final airflows were determined from velocity pressure traverses as described in the apparatus and calculated using Equation 3. To obtain the final airflows presented in Table IV, the author needed to perform additional velocity pressure traverses after balancing. In the field, the practitioner would only take the velocity pressure before balancing.

As expected, the hood static pressure results are predictive of the airflow results (see Equation 4). As can be seen in Table VI, nearly perfect distributions ( $<3 \%$ deviations from desired percentage of the total flow for any branch) were produced. Using the "Target Hood Static Pressure" method, the practitioner aims to achieve the goal hood static pressures calculated by Equation 4. The hood static pressures after the first round are compared with the goals using Equation 10. After the second round, the final hood static pressures compare to the goals using Equation 11.

The "Target Hood Static Pressure" method assumes that $\mathrm{SPh}_{\mathrm{i}} / \mathrm{SPh}_{\text {goal (i) }}$ is related to the square root of $\mathrm{Q}_{\mathrm{i}} / \mathrm{Q}_{\mathrm{goal}(\mathrm{i})}$. This assumption greatly simplifies the balancing process because the hood static pressure is easily taken with a single reading. The determination of airflow, on the other hand, requires velocity pressure traverses and calculation using Equation 3.

Table IV demonstrates how the airflows and the hood static pressures progress from their original values, through the one-and-one-half rounds to their final observations. After the first round, the hood static pressures were close to the goals, the ratios to the goals varying up to $7.5 \%$ above and below in each trial. Since the errors at the end of the first round extend on both the positive and negative sides, some of the hood static pressures were raised, and others lowered in the second round. The accord of the ratios of observed hood static pressures and airflows to their respective goals reflects the perfection of the airflow distribution. 
Table IV - Hood Static Pressure and Airflow Results

(airflows in $\mathrm{ft}^{3} / \mathrm{min}$, Hood Static Pressures in inches water gage)

\begin{tabular}{|c|c|c|c|c|c|c|c|c|c|c|c|c|}
\hline \multirow[b]{2}{*}{ 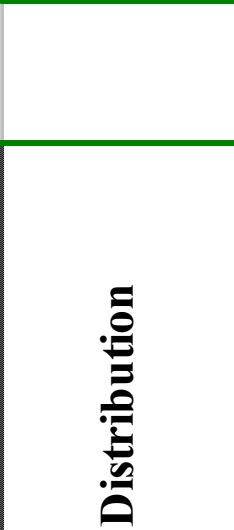 } & \multirow[b]{2}{*}{ లే } & \multicolumn{3}{|c|}{ Airflows } & \multicolumn{4}{|c|}{$\begin{array}{c}\text { Hood Static } \\
\text { Pressures }\end{array}$} & \multicolumn{4}{|c|}{ Ratios } \\
\hline & & 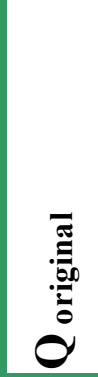 & $\stackrel{\tilde{J}}{\stackrel{\tilde{J}}{\sigma}}$ & 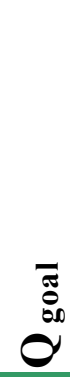 & 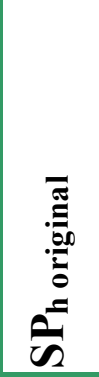 & $\underset{\vec{D}}{\vec{E}}$ & 焉 & 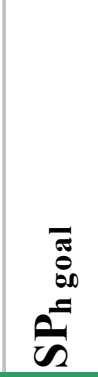 & 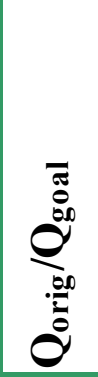 & 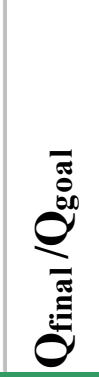 & 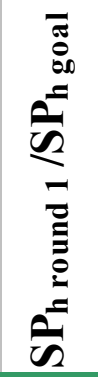 & 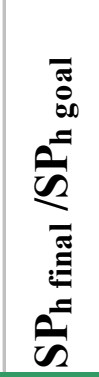 \\
\hline A, replication 1 & 1 & 404.7 & 323.5 & 350 & 0.930 & 0.576 & 0.575 & 0.696 & 1.156 & 0.924 & 0.828 & 0.826 \\
\hline A, replication 1 & 2 & 279.2 & 320.2 & 360 & 0.799 & 1.072 & 1.115 & 1.328 & 0.776 & 0.890 & 0.807 & 0.839 \\
\hline A, replication 1 & 3 & 481.7 & 361.4 & 400 & 0.978 & 0.589 & 0.553 & 0.674 & 1.204 & 0.903 & 0.873 & 0.820 \\
\hline A, replication 1 & 4 & 307.6 & 360.6 & 400 & 1.199 & 1.630 & 1.673 & 2.028 & 0.769 & 0.902 & 0.804 & 0.825 \\
\hline A, replication 1 & 5 & 325.8 & 349.1 & 380 & 1.121 & 1.233 & 1.271 & 1.525 & 0.857 & 0.919 & 0.809 & 0.834 \\
\hline A, replication 1 & 6 & 397.5 & 263.0 & 290 & 0.909 & 0.430 & 0.402 & 0.484 & 1.371 & 0.907 & 0.889 & 0.831 \\
\hline A, replication 1 & 7 & 223.3 & 165.3 & 180 & 0.654 & 0.404 & 0.366 & 0.425 & 1.241 & 0.919 & 0.951 & 0.861 \\
\hline A, replication 2 & 1 & 404.7 & 324.0 & 350 & 0.930 & 0.585 & 0.596 & 0.696 & 1.156 & 0.926 & 0.841 & 0.857 \\
\hline A, replication 2 & 2 & 279.2 & 326.1 & 360 & 0.799 & 1.065 & 1.085 & 1.328 & 0.776 & 0.906 & 0.802 & 0.817 \\
\hline A, replication 2 & 3 & & 367.0 & 400 & 0.978 & 0.594 & 0.571 & 0.674 & 1.204 & 0.917 & 0.881 & 0.847 \\
\hline A, replication 2 & 4 & 307.6 & 356.8 & 400 & 1.199 & 1.633 & 1.665 & 2.028 & 0.769 & 0.892 & 0.805 & 0.821 \\
\hline A, replication 2 & 5 & 325.8 & 346.2 & 380 & 1.121 & 1.249 & 1.258 & 1.525 & 0.857 & 0.911 & 0.819 & 0.825 \\
\hline A, replication 2 & 6 & 397.5 & 264.8 & 290 & 0.909 & 0.431 & 0.416 & 0.484 & 1.371 & 0.913 & 0.891 & 0.860 \\
\hline A, replication 2 & 7 & 223.3 & 165.1 & 180 & 0.654 & 0.408 & 0.370 & 0.425 & 1.241 & 0.917 & 0.960 & 0.871 \\
\hline $\mathrm{B}$, replication 1 & 1 & 404.7 & 440.5 & 500 & 0.930 & 1.088 & 1.116 & 1.420 & 0.809 & 0.881 & 0.766 & 0.786 \\
\hline B, replication 1 & 2 & 279.2 & 220.5 & 250 & 0.799 & 0.533 & 0.501 & 0.641 & 1.117 & 0.882 & 0.832 & 0.782 \\
\hline B, replication 1 & 3 & 481.7 & 456.9 & 520 & 0.978 & 0.910 & 0.908 & 1.140 & 0.926 & 0.879 & 0.798 & 0.797 \\
\hline B, replication 1 & 4 & 307.6 & 201.5 & 225 & 1.199 & 0.467 & 0.512 & 0.642 & 1.367 & 0.895 & 0.728 & 0.798 \\
\hline $\mathrm{B}$, replication 1 & 5 & 325.8 & 290.0 & 330 & 1.121 & 0.929 & 0.926 & 1.150 & 0.987 & 0.879 & 0.808 & 0.805 \\
\hline B, replication 1 & 6 & 397.5 & 396.3 & 450 & 0.909 & 0.909 & 0.903 & 1.165 & 0.883 & 0.881 & 0.780 & 0.775 \\
\hline B, replication 1 & 7 & 223.3 & 241.7 & 275 & 0.654 & 0.788 & 0.788 & 0.992 & 0.812 & 0.879 & 0.795 & 0.795 \\
\hline B, replication 2 & 1 & 404.7 & 457.4 & 500 & 0.930 & 1.105 & 1.139 & 1.420 & 0.809 & 0.915 & 0.778 & 0.802 \\
\hline B, replication 2 & 2 & 279.2 & 220.7 & 250 & 0.799 & 0.543 & 0.506 & 0.641 & 1.117 & 0.883 & 0.848 & 0.790 \\
\hline B, replication 2 & 3 & 481.7 & 464.7 & 520 & 0.978 & 0.921 & 0.904 & 1.140 & 0.926 & 0.894 & 0.808 & 0.793 \\
\hline B, replication 2 & 4 & 307.6 & 199.7 & 225 & 1.199 & 0.454 & 0.510 & 0.642 & 1.367 & 0.888 & 0.708 & 0.795 \\
\hline B, replication 2 & 5 & 325.8 & 294.1 & 330 & 1.121 & 0.931 & 0.918 & 1.150 & 0.987 & 0.891 & 0.810 & 0.798 \\
\hline B, replication 2 & 6 & 397.5 & 393.6 & 450 & 0.909 & 0.924 & 0.913 & 1.165 & 0.883 & 0.875 & 0.793 & 0.784 \\
\hline
\end{tabular}


The column of Table IV labeled with the ratios of Qorig to Qgoal show how far the airflow distributions are from perfect balance. At the end of round one, the ratios of $\mathrm{SP}_{\mathrm{h}}$ round 1 to $\mathrm{SP}_{\mathrm{h} \text { goal }}$ cluster around 0.8 . By the end of the balancing trials, the $\mathrm{SP}_{\mathrm{h}}$ final to $\mathrm{SP}_{\mathrm{h} \text { goal }}$ ratios vary $2 \%$ to $5 \%$ from each other-indicating the usefulness of the second pass in perfecting the distribution. The ratios of $Q_{\text {final }}$ to $Q_{\text {goal }}$ confirm that all airflow ratios equal within 2\%. This demonstrates that the proper distribution is reached. Since these airflow ratios cluster around 0.9 , the fan airflow needs to be increased. None of the branches met its minimal airflow requirement, yet the desired distribution has been reached. In order to make all the rations equal at least one, the fan speed must be increased.

The target hood static pressures for the first round of damper adjustment do not equal the goals. All final observed values of hood static pressure except for the last one in the series are greater than the target. The reason for this, as stated earlier, is that the changing of damper settings changes the resistances to airflow consequently changing all airflows. In distribution " $\mathrm{A}$ ", branch 6, which was balanced first, had a large difference between its target and observed hood static pressure. The observed hood static pressure of branch 4, which placed last in the balancing order, equaled its target in both trials. This trend also holds true in distribution " $\mathrm{B}$ ". Here, the differences between the target and observed $\mathrm{SP}_{\mathrm{h}}$ decrease down the sequence from the first (branch 5) to the last (branch 1). 


\section{Discussion}

This method expects the practitioner balancing the system to stop with the analysis of the final hood static pressure values presented in Table IV of the results section. However, to verify the efficacy of the method, this study included determination of final airflows. This section analyses the final airflow distributions from the balancing trials.

Table $\mathrm{V}$ shows the results of the four balancing trials in terms of airflow distribution. The original, final and goal fractions of total airflows are presented along with terms expressing the shift in fractions of total airflow from $\mathrm{Q}_{\text {original }}$ to $\mathrm{Q}_{\text {final }}$ and from $\mathrm{Q}_{\text {original }}$ to $\mathrm{Q}_{\text {goal. }}$. The differences between shifts in fraction of airflow show if the branch resulted in having greater than or less than its goal share of total airflow.

The percent distribution error is the percentage of the branch's fraction of total final airflow that exceeds that branch's goal fraction. Given that the branch that is most starved of airflow meets its goal airflow (after the fan speed is adjusted), the other branches will exceed their goal airflows by the percent distribution error. If the goal airflow distribution is perfect, then the distribution error for each branch will be zero.

In Table $\mathrm{V}$, one sees the changes in airflow distribution from the original to the final measurements. Additionally, the results demonstrate that the assumption that $\mathrm{SPh}_{\mathrm{i}} / \mathrm{SPh}_{\text {goal(i) }}$ is related to the square root of $\mathrm{Q}_{\mathrm{i}} / \mathrm{Q}_{\text {goal(i) }}$ is accurate. The shifts in the fraction of distribution from the original to the goal airflows and to the final observed airflows are varied. The relative shifts in airflow are in some cases marked. In distribution "A" the differences between $Q_{\text {orig }}$ and $Q_{\text {final }}$ range from $-27.1 \%$ of Q Qrig in branch 6 to $30 \%$ in branch 4 . In distribution "B", the differences between $\mathrm{Q}_{\text {orig }}$ and $\mathrm{Q}_{\text {final }}$ range from $-26.8 \%$ of $\mathrm{Q}_{\text {orig }}$ in branch 4 to $+23.6 \%$ in branch 1 .

The three columns with the fractions of total airflow show how the total airflow is distributed among the branches initially, after the balancing trials and among the goal airflows. The fact that the final fractions of airflow correspond to the goals reinforces the airflow results presented in the Results section. The actual shift in goal airflow from the original airflow was within hundredths what it should have been in each branch for each trial. 
Table V - Distribution of Airflow results (airflows in $\mathrm{ft}^{3} / \mathbf{m i n}$ )

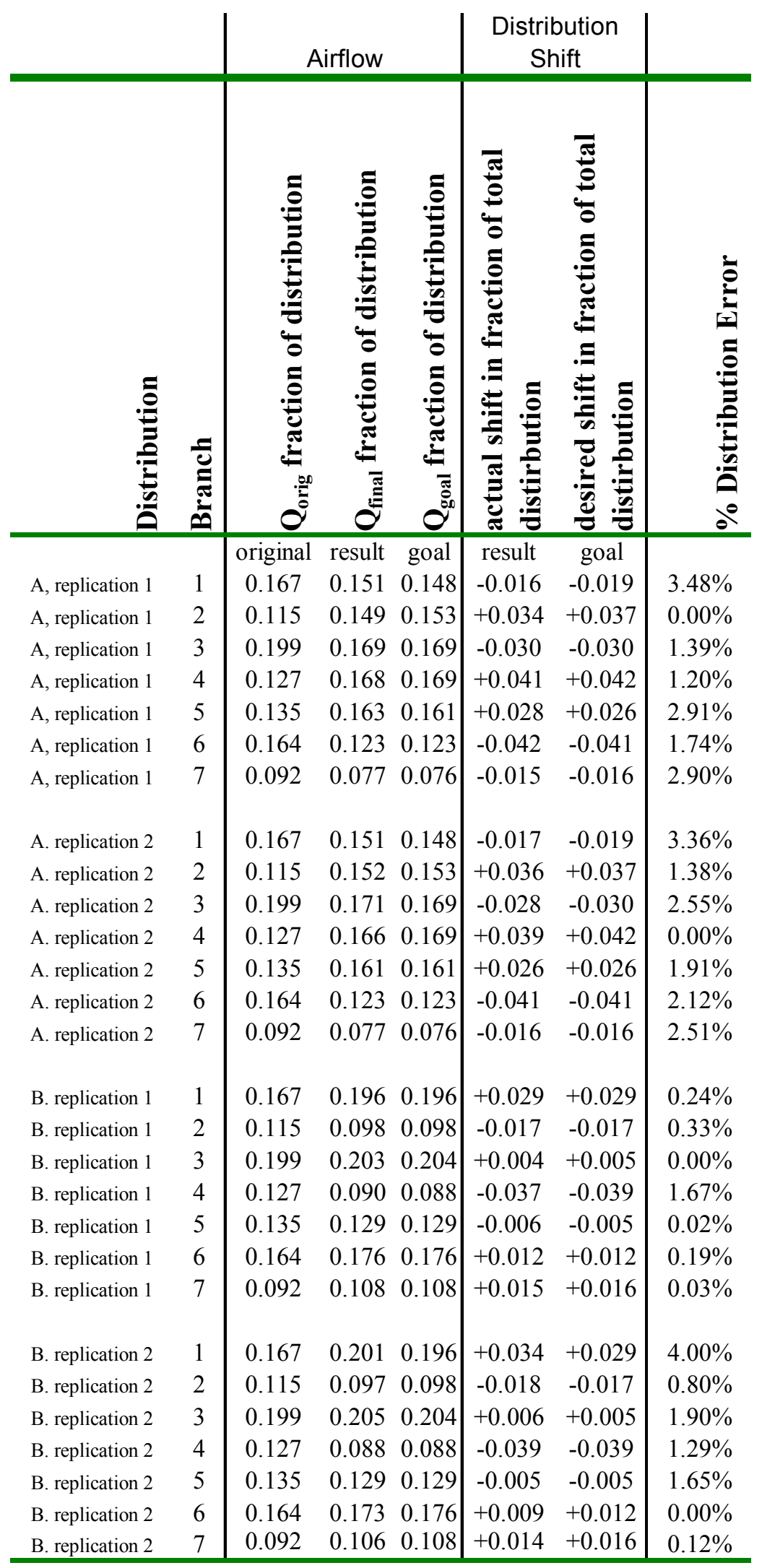




\section{Table VI - Maximum and Root Mean Square Errors}

\begin{tabular}{|c|c|c|c|}
\hline Distribution & RMS error & $\begin{array}{c}\text { Maximum } \\
\text { Error in } \\
\text { any Branch }\end{array}$ & $\begin{array}{c}\text { Fraction } \\
\text { Wasted }\end{array}$ \\
\hline A-1 & $1.24 \%$ & $3.48 \%$ & $2.09 \%$ \\
\hline A-2 & $1.09 \%$ & $3.36 \%$ & $2.13 \%$ \\
\hline B-1 & $0.63 \%$ & $1.67 \%$ & $0.30 \%$ \\
\hline B-2 & $1.43 \%$ & $4.00 \%$ & $1.82 \%$ \\
\hline
\end{tabular}

The maximum distribution error listed in Table VI is for that branch which had the most excessive airflow. The greatest maximum error of $4.00 \%$ occurred in branch 1 during the second trial of distribution B (see Table VI). The other maximum errors ranged from $1 \frac{1}{2}$ to $3 \frac{1}{2}$ percent. These maximum errors fall under the 5\% airflow shift level recommended by the ACGIH ventilation manual (ACGIH 2001, p. 9-45). Statistical analysis to make confidence intervals is difficult because the branch airflows are mutually dependent. The error in one branch partially determines the error in another branch. Thus, an independent variable with which to compare each branch could not be identified.

Included in Table VI is the measure of the fraction wasted (Equation 1). As described in the Introduction, the fraction wasted is the fraction of the total airflow that exceeds the minimally needed fan output. In other words, to bring the most "starved" branch to its minimum required airflow, one needs to regulate the fan output by the inverse of $\mathrm{Q}_{\mathrm{i}} / \mathrm{Q}_{\text {goal(i) }}$ so that the fraction wasted is zero. This means that the distribution is not changed, but that every branch has at least its minimally required airflow to meet the hood capturing and settlement prevention velocity requirements that are the basis of the choice of goal airflows for each branch.

The final distribution error can be attributed to errors in the method or in measurement. Method error is imperfection in the method that causes the resulting distribution to stray from the goal distribution. Method error may lie in the mathematical calculations, approximations or assumptions of the method. Measurement error is any digression between the values measured from the actual quantities. Many occasions in this study present opportunity for measurement error. Measurements were made of many parameters including temperature, pressure, velocity pressure, static pressure and distance. For pitot traverse measurements under controlled conditions, $90 \%$ of measurement error falls within $\pm 3 \%$ of the true value (Guffey and Booth, 
1999). The distribution errors all fall into a range $4 \%$ wide (see Table VI). The range of distribution error is narrower than the range of measurement error. Therefore, a perfect method cannot be demonstrated as better. 


\section{Bibliography}

Besant, R. W. and Asiedu, Y. (2000). Sizing and Balancing Air Duct Systems. American Society of Heating, Refrigeration and Air Conditioning Engineers Journal (December 2000): pp 24-36.

Crowder, J. W. and Loudermilk, K. J. (1982) Balancing of Industrial Ventilation Systems. Journal of the Air Pollution Control Association Volume 32. No 1. (January 1982): pp 115-117.

Guffey, S. E. and Booth, D. W. (1999) Comparison of Pitot Traverses Taken at Varying Distances Downstream of Obstructions. American Industrial Hygiene Association Journal. Vol. 60, No. 2. (1999): pp. 165-174.

Guffey, S.E.; Slagley, Jeremy; Balasubramanian, Vivek; El-Sotouhy, Ahmed; Sivanagere, Sumeeth; Dodrill, Michael (2004). Damper Adjustment in Vent Systems without Prior System Modeling. unpublished manuscript. July 2004.

Guffey, S. E. and Hickey, J. L. S. (1983). Equations for Redesign of Existing Ventilation Systems. American Industrial Hygiene Association Journal 44(11):819-827. (1983): pp 819-127.

Guffey, S. E. (1993). Air-Flow Redistribution in Exhaust Ventilation Systems Using Dampers and Static Pressure Ratios. Applied Occupational Environmental Hygiene 8(3) (March 1993): pp 168-177.

Guffey, S. E. (1990). Simplifying Pitot Traverses. Applied Occupational Environmental Hygiene 5(2). (February 1990): pp 95-100.

Haines, R. (1988). Heating, Ventilation and Air Conditioning Systems Design Handbook. Published by TAB Books Incorporated.

Jorgensen, R. (editor) (1983). Fan Engineering. Eighth Edition. Published by Buffalo Forge Company.

McLoone, H.E.; Guffey, S.E. and Curran, J.C. (1993). Effects of Shape, Size, and Air Velocity on Entry Loss Factors of Suction Hoods. American Industrial Hygiene Association Journal, 54(3):87-94 (1993).

American Conference of Governmental Industrial Hygienists (2001). Industrial Ventilation-A Manual of Recommended Practice 24th Edition. Published by the ACGIH.

American Society of Heating. Refrigerating and Air-Conditioning Engineers. Inc. (1995). 1995 ASHRAE Handbook Heating, Ventilating, and Air-Conditioning Applications. Published by ASHRAE.

Sheet Metal and Air Conditioning Contractors' National Association. Inc. (1993). HVAC Systems-Testing. Adjusting and Balancing. Published by SMACNA. 
Sheet Metal and Air Conditioning Contractors' National Association. Inc. (2002). HVAC Systems-Testing. Adjusting and Balancing. Published by SMACNA.

Sheet Metal and Air Conditioning Contractors' National Association Inc. (2003). Testing and Balancing Procedural guide. Published by SMACNA. 


\section{Appendix, Calibration of the Digital Manometer}

\section{Equipment:}

Digital Manometer: TSI DP-Calc. digital manometer Model: 8702 Serial: 96071045

Hook Gage: Dwyer Instruments Inc. Pressure N ${ }^{\circ} 1425$ Hook Gage.

Calibration Data for the Determination of the Original Distribution and

\section{Calibration Verification}

\begin{tabular}{|c|c|c|c|}
\hline Trial & Date & $\begin{array}{c}\text { Gage Water } \\
\text { Level }\end{array}$ & $\begin{array}{l}\text { Manometer } \\
\text { Reading }\end{array}$ \\
\hline & yyyy.mm.dd & inches & inches \\
\hline \multirow[t]{10}{*}{ Original } & \multirow[t]{10}{*}{2004.04 .07} & 0.25 & 0.245 \\
\hline & & 0.5 & 0.487 \\
\hline & & 0.75 & 0.742 \\
\hline & & 1 & 0.983 \\
\hline & & 1.5 & 1.484 \\
\hline & & 2 & 2.967 \\
\hline & & 3 & 3.477 \\
\hline & & 4 & 3.973 \\
\hline & & 5 & 4.957 \\
\hline & & 6 & 5.965 \\
\hline \multirow{10}{*}{ Original } & \multirow[t]{10}{*}{2004.05 .04} & 0.25 & 0.250 \\
\hline & & 0.5 & 0.500 \\
\hline & & 0.75 & 0.745 \\
\hline & & 1 & 0.994 \\
\hline & & 1.5 & 1.490 \\
\hline & & 2 & 1.987 \\
\hline & & 3 & 2.986 \\
\hline & & 4 & 3.979 \\
\hline & & 5 & 4.974 \\
\hline & & 6 & 5.971 \\
\hline \multirow[t]{10}{*}{ Calibration Verification } & \multirow{10}{*}{2004.07 .09} & 0.25 & 0.262 \\
\hline & & 0.5 & 0.520 \\
\hline & & 0.75 & 0.771 \\
\hline & & 1 & 1.001 \\
\hline & & 1.5 & 1.504 \\
\hline & & 2 & 2.007 \\
\hline & & 3 & 3.008 \\
\hline & & 4 & 4.001 \\
\hline & & 5 & 5.005 \\
\hline & & 6 & 6.002 \\
\hline
\end{tabular}


Calibration Data for the Measurements of the Balancing Trials

\begin{tabular}{|c|c|c|c|}
\hline Trial & Date & $\begin{array}{c}\text { Gage Water } \\
\text { Level }\end{array}$ & $\begin{array}{l}\text { Manometer } \\
\text { Reading }\end{array}$ \\
\hline & yyyy.mm.dd & inches & inches \\
\hline \multirow[t]{10}{*}{ A, replication 1} & 2004.04 .23 & 0.25 & 0.251 \\
\hline & & 0.5 & 0.497 \\
\hline & & 0.75 & 0.758 \\
\hline & & 1 & 1.000 \\
\hline & & 1.5 & 1.494 \\
\hline & & 2 & 2.000 \\
\hline & & 3 & 2.983 \\
\hline & & 4 & 3.980 \\
\hline & & 5 & 4.981 \\
\hline & & 6 & 5.979 \\
\hline \multirow[t]{10}{*}{ A, replication 2} & 2004.05 .02 & 0.25 & 2.640 \\
\hline & & 0.5 & 0.509 \\
\hline & & 0.75 & 0.758 \\
\hline & & 1 & 1.003 \\
\hline & & 1.5 & 1.505 \\
\hline & & 2 & 2.006 \\
\hline & & 3 & 2.999 \\
\hline & & 4 & 3.998 \\
\hline & & 5 & 4.990 \\
\hline & & 6 & 5.991 \\
\hline \multirow[t]{10}{*}{ B, replication 1} & 2004.04 .23 & 0.25 & 0.251 \\
\hline & & 0.5 & 0.497 \\
\hline & & 0.75 & 0.758 \\
\hline & & 1 & 1.000 \\
\hline & & 1.5 & 1.494 \\
\hline & & 2 & 2.000 \\
\hline & & 3 & 2.983 \\
\hline & & 4 & 3.980 \\
\hline & & 5 & 4.981 \\
\hline & & 6 & 5.979 \\
\hline \multirow[t]{10}{*}{ B, replication 2} & 2004.05 .03 & 0.25 & 0.247 \\
\hline & & 0.5 & 0.497 \\
\hline & & 0.75 & 0.746 \\
\hline & & 1 & 0.994 \\
\hline & & 1.5 & 1.493 \\
\hline & & 2 & 1.992 \\
\hline & & 3 & 2.982 \\
\hline & & 4 & 3.981 \\
\hline & & 5 & 4.975 \\
\hline & & 6 & 5.976 \\
\hline
\end{tabular}

